\title{
New diplodocoid sauropod dinosaur material from the Middle Jurassic of European Russia
}

\author{
Alexander O. Averianov and Nikolay G. Zverkov \\ Acta Palaeontologica Polonica 65 (3), 2020: 499-509 doi:https://doi.org/10.4202/app.00724.2020
}

Two anterior caudal vertebrae from apparently a single individual from the Callovian (Middle Jurassic) marine deposits of the Podosinki Formation at Peski Quarry near Moscow, Russia, are attributed by the phylogenetic analyses of two independent datasets to the sauropod clade Diplodocoidea. Morphologically, these vertebrae differ from the anterior caudals of Diplodocidae and Rebbachisauridae, but are similar to those of Dicraeosauridae. This finding is in line with a recent discovery of the dicraeosaurid sauropod Lingwulong from the late Early-early Middle Jurassic of China, and suggests earlier diversification of the main neosauropod lineages and Asiatic origin for Dicraeosauridae. The Peski sauropod is the first Jurassic terrestrial vertebrate from the Fennoscandian landmass. Diplodocoid sauropods likely dispersed to this land massive before the Bathonian, when it was still connected with Asia.

Key words: Dinosauria, Sauropoda, Diplodocoidea, Mesozoic, Russia, Fennoscandian landmass.

Alexander O. Averianov [dzharakuduk@mail.ru], Zoological Institute of the Russian Academy of Sciences, Universitetskaya Emb. 1, 199034 Saint Petersburg, Russia. Nikolay G. Zverkov [zverkovnik@mail.ru], Borissiak Paleontological Institute of the Russian Academy of Sciences, Profsouznaya Str. 123, 117997 Moscow, Russia; Geological Institute of the Russian Academy of Sciences, Pyzhevsky lane 7, 119017 Moscow, Russia.

This is an open-access article distributed under the terms of the Creative Commons Attribution License (for details please see creativecommons.org), which permits unrestricted use, distribution, and reproduction in any medium, provided the original author and source are credited. 
FaF Full text $(11,893.2 \mathrm{kB})$ 